\title{
Investigasi Anomali TEC-Ionosfer Sebelum Letusan Gunung Lokon 14 Juli 2011 Menggunakan Metode Sliding Interquartile
}

\author{
Christian Imanuel Angoa, Dolfie Paulus Pandaraa, Ferdya, Seni Herlina Juita \\ Tongkukuta \\ aJurusan Fisika FMIPA Universitas Sam Ratulangi
}

KATA KUNCI

Gunung Lokon

Anomali TEC-lonosfer,

Metode Sliding Interquartile, Prekursor Erupsi.

\begin{abstract}
A B S T R A K
Gunung Lokon yang berada di Sulawesi Utara adalah salah satu gunung api yang sering mengalami erupsi di Indonesia. Sebelum erupsi terjadi, terdapat aktivitas praerupsi yang memicu munculnya anomali Total Electron Content (TEC) di ionosfer. Anomali TEC yang menandai terjadinya letusan diasumsikan sebagai prekursor erupsi yang dapat bermanfaat bagi upaya mitigasi bencana letusan. Tujuan penelitian ini adalah untuk menginvestigasi anomali TEC sebelum letusan gunung Lokon pada tanggal 14 Juli 2011. Investigasi anomali TEC menggunakan metode Sliding Interquartile diperoleh hasil yang menunjukkan adanya anomali TEC yang terjadi 3 hari menjelang letusan yaitu pada tanggal 11 Juli 2011. Hal ini mengindikasikan adanya aktivitas pra-erupsi yang berpengaruh pada kuantitas TEC di ionosfer.

A B S T R A C T

Mount Lokon, located in North Sulawesi is among the most active volcanoes in Indonesia. Before the eruption occurred, there was a pre-eruption activity that triggered anomaly on Total Electron Content (TEC) in the ionosphere. TEC anomaly that mark the eruption are assumed as precursors of eruption that can be useful for disaster eruption mitigation efforts. The purpose of this study was to investigate the TEC anomaly before the Lokon eruption on July 14, 2011. Investigation of TEC by using the Sliding Interquartile method, the results showed that an TEC anomaly occurred 3 days before the eruption on July 11, 2011.These indicates the presence of pre-eruptive activity that affects the quantity of TEC in the ionosphere.
\end{abstract}

K E Y W O R D S

Mount Lokon

TEC-lonosfer Anomaly,

Sliding Interquartile Method,

Eruption Precursor.
TERSEDIA ONLINE

01 Februari 2020

\section{Pendahuluan}

Gunung Lokon yang berlokasi di Tomohon Sulawesi Utara memiliki rekam jejak erupsi yang sering terjadi (Kristianto dkk., 2012). Letusan magmatik dengan tipe vulkanian terjadi pada tanggal 14 Juli 2011 pukul 23.31 WITA atau 15.31 UTC (Coordinated Universal Time). Tinggi kolom letusan mencapai $1.500 \mathrm{~m}$ di atas kawah dan melontarkan material pijar yang membakar hutan hingga radius sekitar 500 m dari kawah. Letusan ini disusul dengan letusan kedua yang berselang kurang dari 1 menit, berupa letusan abu tebal dengan ketinggian mencapai $700 \mathrm{~m}$ dari atas kawah (Kristianto dkk., 2012).

Sebelum letusan terjadi terdapat aktivitas preseismik berupa pelepasan ion-ion positif yang berpotensi memicu anomali Total Electron Content
(TEC) (Akhoondzadeh, 2012; Nenovski dkk., 2014 dan Li dkk., 2016). TEC adalah jumlah elektron dalam kolom vertikal (silinder) yang berpenampang seluas $1 \mathrm{~m}^{2}$ sepanjang lintasan sinyal dalam lapisan ionosfer. Nilai TEC dinyatakan dalam satuan TEC Unit (TECU) dengan 1 TECU mengandung $10^{16}$ elektron $/ \mathrm{m}^{2}$. Kisaran nilai TEC di ionosfer dalam keadaan normal adalah antara 1 hingga 200 TECU (Abidin, 2000). Penentuan TEC di ionosfer terbagi ke dalam dua jenis, yakni slant TEC dan vertical TEC. Slant TEC (STEC) adalah jumlah kandungan elektron di titik silang antara sinyal satelit dengan jejari bumi (lonospheric Pierce Point) yang diamati dari stasiun penerima GPS dengan posisi membentuk sudut inklinasi $E$ terhadap satelit GPS. Sementara itu, vertikal TEC (VTEC) adalah jumlah kandungan total elektron yang diamati secara vertikal dari titik sub- 
ionosferik (sub-ionospheric point) terhadap Ionospheric Pierce Point. Anomali TEC disebabkan oleh naiknya gas radon ke permukaan gunung bersamaan dengan naiknya magma dan kemudian menyebabkan terjadi proses ionisasi atmosfer dan perubahan konduktivitas udara. Bila proses ini terjadi pada daerah lintang rendah (dekat ekuator magnet bumi) akan menimbulkan medan listrik horizontal. Medan listrik yang mengarah ke timur menyebabkan drift elektromagnet $(E \times B)$ bergerak vertikal dan mendorong naiknya plasma menuju pada ketinggian (altitude) yang lebih tinggi sehingga meningkatkan konsentrasi TEC di ionosfer, sebaliknya apabila medan listrik mengarah ke barat akan menyebabkan menurunnya kandungan TEC (Gasparini dan Mantovani, 1978 ; Li dkk., 2016). Li dkk., (2016) menemukan adanya anomali TEC 6-17 hari sebelum terjadinya erupsi gunung api, dimana anomali tersebut lebih sering terjadi pada daerah lintang rendah. Selain erupsi gunung api, anomali TEC juga terjadi akibat adanya gempa bumi, tsunami, dan badai geomagnet (Li dkk., 2016). Erupsi gunung api, gempa bumi, tsunami merupakan peristiwa geofisika yang terjadi di litosfer dan dapat mempengaruhi TEC.

Badai geomagnet merupakan gangguan yang terjadi pada medan magnet bumi akibat pengaruh Iontaran massa korona dari matahari. Klasifikasi aktivitas badai geomagnet dapat dilihat berdasarkan indeks DST yang terdapat pada Tabel 1. Indeks DST (Disturbance Strom Time) adalah rata - rata dari variasi pada komponen horisontal bidang geomagnetik yang diukur dengan near-equatorial geomagnetic Observatories (Sulastri dkk., 2017).

Tabel 1. Data Klasifikasi Badai Geomagnet Berdasarkan Indeks DST.

\begin{tabular}{|l|l|l|}
\hline No. & $\begin{array}{l}\text { Kategori Badai } \\
\text { Magnet }\end{array}$ & $\begin{array}{l}\text { Rentang Indeks DST } \\
(\mathrm{nT})\end{array}$ \\
\hline 1. & Lemah & $-30 \geq D S T>-50$ \\
\hline 2. & Moderat (Sedang) & $-50 \geq D S T>-100$ \\
\hline 3. & Kuat & $-100 \geq D S T>-200$ \\
\hline 4. & $\begin{array}{l}\text { Severe (Sangat } \\
\text { Kuat) }\end{array}$ & $-200 \geq D S T>-300$ \\
\hline 5. & Super & $D S T \leq-300$ \\
\hline
\end{tabular}

Sumber : Sulastri dkk., (2017).

Munculnya anomali dapat dianggap sebagai early warning dalam upaya mitigasi bencana alam khususnya untuk daerah-daerah di Indonesia. Penelitian ini menginvestigasi anomali TEC yang menjadi prekursor erupsi gunung Lokon pada tanggal 14 Juli 2011 sebagai salah satu upaya mitigasi bencana erupsi.

\section{Material dan Metode Penelitian \\ Data}

Identifikasi adanya anomali TEC yang merupakan prekursor letusan gunung Lokon menggunakan beberapa data, yakni data vertikal TEC, data gempa bumi, data letusan, dan data indeks DST. Kecuali data VTEC, data-data diatas digunakan untuk menentukan kemungkinan penyebab anomali TEC. Data VTEC yang disediakan oleh IONOLAB-TEC
(http://ionolab.org/webTEC/single.html) merupakan data yang berasal dari stasiun pengamatan TEC yang tersebar di berbagai belahan dunia. IONOLAB-TEC merupakan aplikasi JAVA yang dikembangkan oleh Departement of Electrical Engineering of Hacettepe University, Ankara, Turki (Arikan dkk., 2003). Data VTEC dalam penelitian ini dikhususkan hanya pada data yang berasal dari stasiun BAKO, PIMO, dan DARW (Gambar 1) dengan resolusi data sebesar 150 detik.

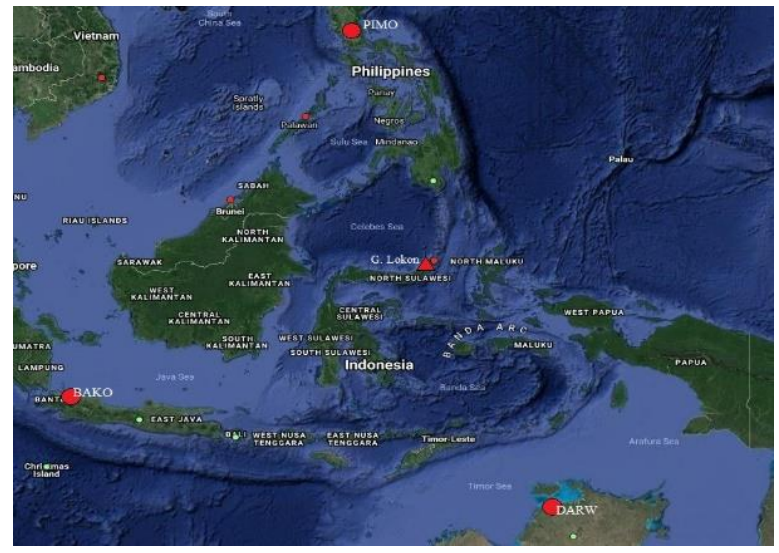

Gambar 1. Peta sebaran stasiun IGS yang digunakan dalam pengamatan variasi TEC gunung Lokon.

Data DST diperoleh dari WDC Geomagnetic, Kyoto University (wdc.kugi.kyoto-u.ac.jp). Data gempa gumi dengan $\mathrm{M} \geq 6,0$ pada rentang wilayah $24,5^{\circ} \mathrm{LU}-25^{\circ}$ LS serta 90,7 BT - 139,570 BT diakses melalui https://earthquake. usgs.gov/earthquakes/search/. Data letusan gunung api di Indonesia dan sekitarnya diakses melalui https://volcano.si.edu/database/ search eruption results.cfm. Data-data yang digunakan penelitian ini adalah data yang tersedia selama kurun periode observasi. Periode observasi dimulai dari 30 hari sebelum letusan sampai 3 hari setelah letusan.

Tabel 2. Data Gempa Bumi Selama Periode Observasi.

\begin{tabular}{|c|c|c|c|c|c|}
\hline Tanggal & Jam (UTC) & Lintang $\left(^{\circ}\right)$ & Buiur $\left({ }^{\circ}\right)$ & $\begin{array}{c}\text { Kedalaman } \\
(\mathrm{Km})\end{array}$ & $\begin{array}{c}\text { Magnitudo } \\
\text { Gempa }\end{array}$ \\
\hline 26/06/2011* & $12: 16: 38$ & -2.384 & 136.631 & 17 & 6.3 \\
\hline $11 / 07 / 2011^{*}$ & $20: 47: 04$ & 9.509 & 122.175 & 19 & 6.4 \\
\hline
\end{tabular}

Sumber : * USGS, (2011).

Tabel 3. Data Erupsi Selama Periode Observasi.

\begin{tabular}{|c|c|c|c|c|c|}
\hline Tanggal & $\begin{array}{c}\text { Jam } \\
\text { (Waktu } \\
\text { Lokal) }\end{array}$ & Gunung & $\begin{array}{c}\text { Lintang } \\
\left({ }^{\circ}\right)\end{array}$ & Bujur $\left(^{\circ}\right)$ & VEI \\
\hline $14 / 06 / 2011$ & $?$ & Semeru* & -8.108 & 112.922 & 2 \\
\hline $17 / 06 / 2011$ & $?$ & Semeru* & -8.108 & 112.922 & 2 \\
\hline $03 / 07 / 2011$ & $06: 03$ & Soputan** & 1.112 & 124.737 & 3 \\
\hline $14 / 07 / 2011$ & $23: 31$ & Lokon*** & 1.358 & 124.792 & 2 \\
\hline 03/08/2011 & $?$ & Marapi**** & -0.38 & 100.474 & 2 \\
\hline
\end{tabular}

Sumber :

* Global Volcanism Program (2017).

** Global Volcanism Program (2011).

*** Global Volcanism Program (2015b).

$\star * * *$ Global Volcanism Program (2015a).

\section{Metode}


Deteksi anomali TEC dilakukan menggunakan metode statistik Sliding Interquartile. Metode tersebut telah digunakan beberapa peneliti sebelumnya (Akhoondzadeh, 2012; Nenovski dkk., 2014; Li dkk., 2016). Metode ini menggunakan nilai median dan jarak antar kuartil untuk mengestimasi nilai toleransi (batas atas dan batas bawah) dari data TEC. Penentuan batas atas (Upper Bound) dan batas bawah (Lower Bound) dilakukan dengan menggunakan rumus :

$$
\begin{aligned}
& \text { Upper Bound }(U B)=m+2 \cdot I Q R \\
& \text { Lower Bound }(L B)=m-2 \cdot I Q R
\end{aligned}
$$

dimana, $\mathrm{m}$ adalah nilai median TEC (TECU), IQR adalah jangkauan antar kuartil TEC. Pengambilan nilai 2 kali besar interquartile adalah sebagai nilai toleransi (sekitar 2,68 standar deviasi) (Li dkk., 2016). Nilai VTEC kemudian diplot bersama dengan nilai $U B$ dan nilai $L B$. Nilai TEC lebih besar dari nilai batas atas (Upper Bound) ataupun lebih kecil dari nilai batas bawahnya (Lower Bound) menunjukkan telah terjadi anomali TEC. Anomali ditampilkan dalam bentuk nilai Diferensial TEC (DTEC) yang secara matematis dirumuskan sebagai berikut:

$$
D T E C=\left\{\begin{array}{c}
T E C-U B ; \quad \text { jika } T E C>U B \\
0 ; \quad \text { jika } L B \leq T E C \leq U B \\
T E C-L B ; \quad \text { jika } T E C<L B
\end{array}\right)
$$

DTEC pada setiap stasiun dianalisa untuk menentukan anomali yang merupakan prekursor erupsi. Analisa dilakukan dengan mencocokkan data anomali (DTEC) dengan data indeks DST, data gempa bumi, dan data letusan gunung api. Pencocokkan ini dimaksudkan untuk mendapatkan anomali yang tidak berkaitan dengan kejadian gempa, badai geomagnet, ataupun letusan gunung api selain dari letusan gunung Lokon pada 14 Juli 2011. Proses pengolahan data menggunakan aplikasi Microsoft Excel 2016.

\section{Hasil dan Pembahasan}

Berikut adalah data variasi VTEC, Upper Bound, dan Lower Bound pada periode 14 Juni 2011 sampai 17 Juli 2011 yang diperoleh dari stasiun BAKO.

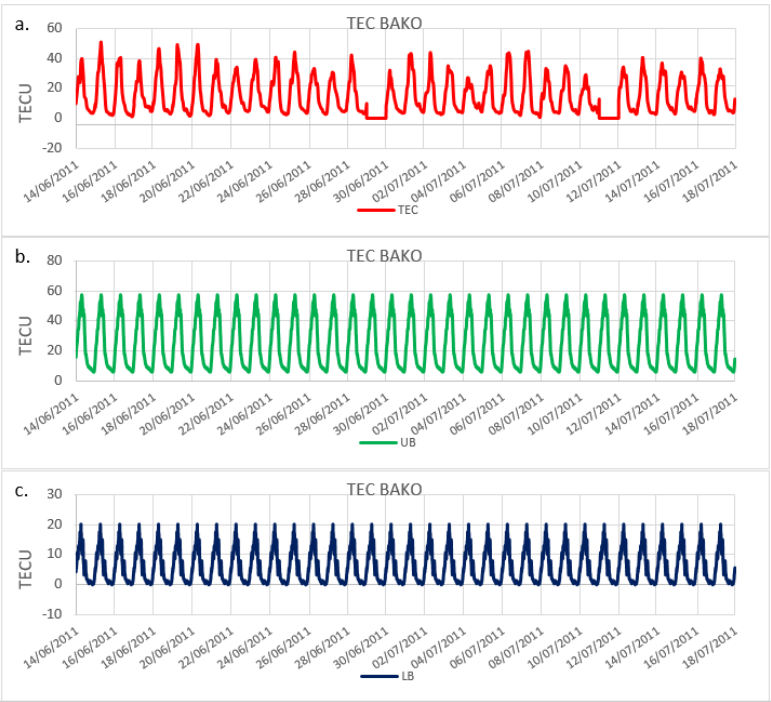

Gambar 2. (a) Variasi nilai VTEC. (b) Upper Bund. (c)

Lower Bound periode 14 Juni 2011 sampa 17 Juli

2011 untuk stasiun BAKO (IONOLAB-TEC, 2011).

Penggabungan data VTEC, Upper Bound, dan Lower Bound untuk stasiun BAKO, DARW, dan PIMO ditunjukkan seperti pada gambar 3 .

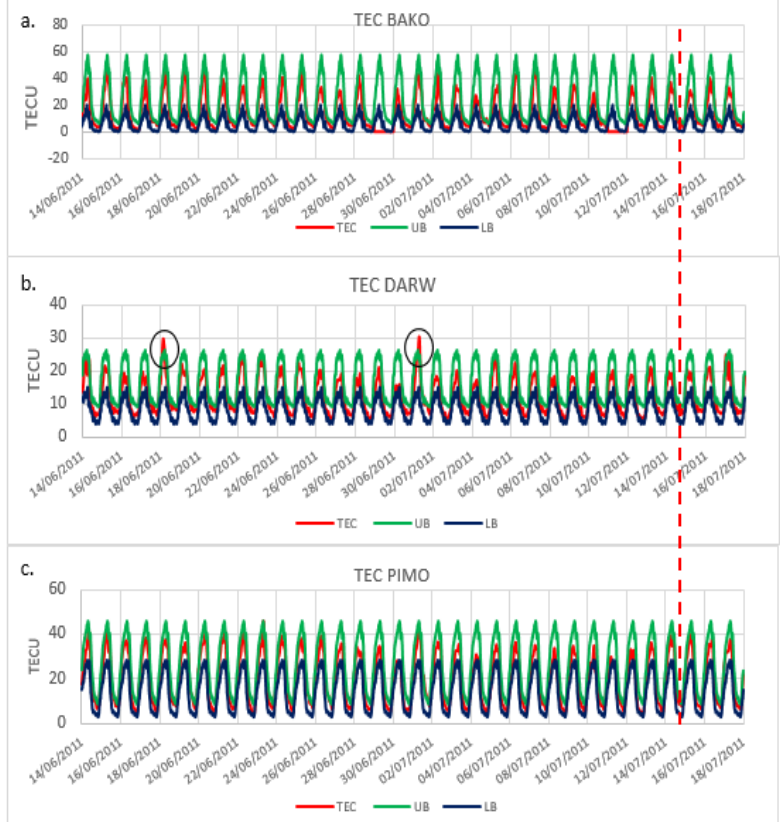

Gambar 3. Variasi nilai VTEC terhadap Upper Bound dan Lower Bound periode 14 Juni 2011 sampai 17 Juli 2011 untuk stasiun : (a.) BAKO (b.) DARW (c.) PIMO (IONOLAB-TEC, 2011).

Gambar 3 menunjukkan variasi nilai VTEC (ditunjukkan oleh garis warna merah) selama 30 hari menjelang letusan dan 3 hari setelah letusan terjadi bersama dengan nilai batas atas (Upper Bound) yang ditunjukkan oleh garis hijau dan batas bawahnya (Lower Bound) yang ditunjukkan oleh garis ungu pada stasiun BAKO, DARW, dan PIMO. Garis merah putus-putus menunjukkan waktu letusan dan lingkaran hitam menunjukkan anomali TEC yang teramati secara langsung. Anomali TEC positif hanya terlihat pada stasiun DARW yaitu pada tanggal 18 Juni 2011 dan 1 Juli 2011, sedangkan pada kedua stasiun lain tidak terlihat adanya anomali secara signifikan. Visualisasi anomali TEC secara detail dilakukan dengan perhitungan DTEC untuk menginvestigasi anomali pada kedua stasiun yang lain. Hasil tersebut ditunjukkan pada gambar 4. 


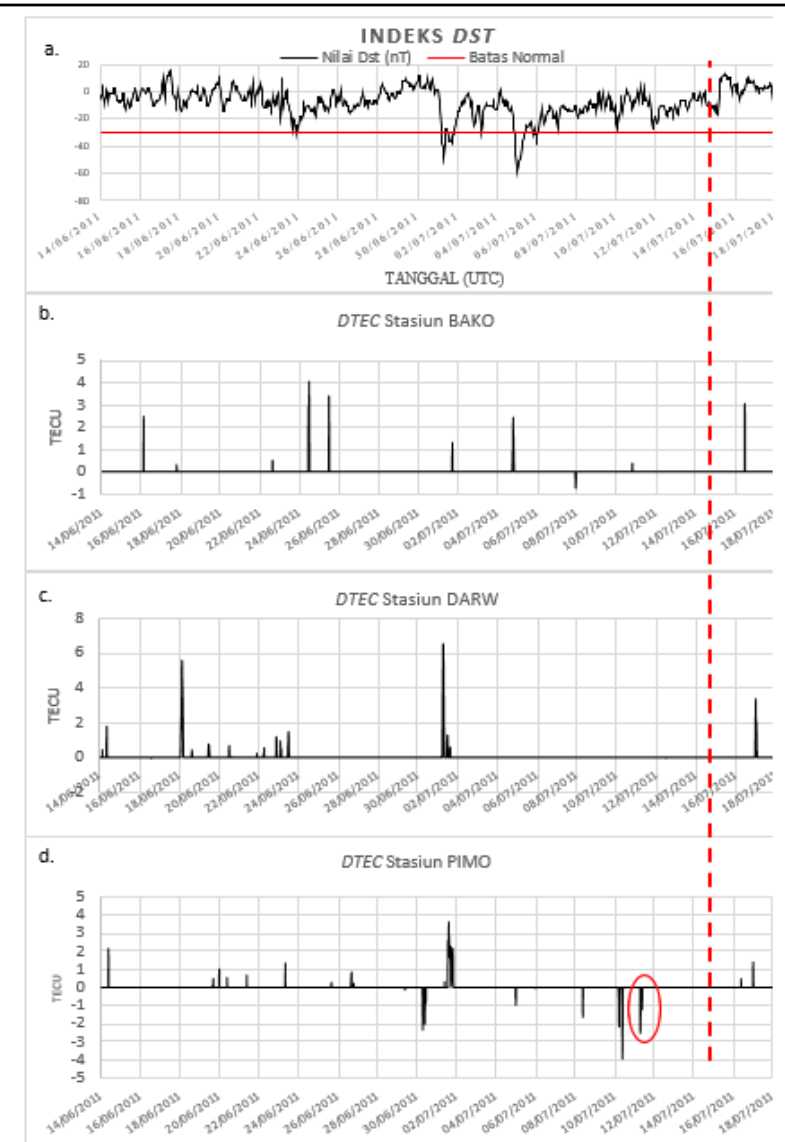

Gambar 4. (a) Variasi Nilai Indeks DST pada tanggal 14 Juni 2011 sampai 17 Juli 2011 (WDC

Geomagnetic, 2011) dan Diferensial TEC pada periode 14 Juni 2011 sampai 17 Juli 2011 untuk stasiun : (b.) BAKO (c.) DARW (d.) PIMO (IONOLABTEC, 2011).

Gambar 4 menununjukkan kondisi geomagnetik selama periode pengamatan 1 Juni 2011 sampai 17 Juli 2011 dimana selama periode tersebut terjadi peningkatan aktivitas pada tanggal 23 Juni, 1 Juli dan 3-5 Juli 2011. Selain itu nilai indeks DST mengalami penurunan yang cukup drastis pada tanggal 10 dan 11 Juni 2011 namun penurunan yang terjadi tidak melewati batas normal sehingga disimpulkan bahwa pada kedua tanggal tersebut tidak terjadi badai geomagnet. Seperti yang telah diketahui bahwa anomali TEC juga diakibatkan oleh badai geomanetik maka anomali yang muncul pada masing-masing tanggal tersebut diasumsikan sebagai anomali akibat badai geomagnetik.

Anomali TEC ditunjukkan oleh nilai DTEC yang tidak sama dengan nol. Nilai DTEC mewakili besar dan tipe anomali yang terjadi. Bila DTEC bernilai positif maka anomali yang terjadi bertipe positif, begitu pula sebaliknya (Li dkk., 2016). Anomali TEC positif terjadi bilamana nilai TEC lebih besar dari pada nilai batas atas (Upper Bound) yang mengindikasikan adanya peningkatan kerapatan elektron di ionosfer secara abnormal. Peningkatan ini disebabkan karena naiknya plasma yang terdorong oleh pergerakan vertikal drift elektromagnet (Li dkk., 2016). Anomali TEC negatif mengindikasikan adanya penurunan kerapatan elektron di ionosfer secara abnormal. Penurunan disebabkan oleh adanya emisi gas radon yang mengandung ion-ion positif ke ionosfer yang kemudian mengikat elektron bebas sehingga menyebabkan berkurangnya kandungan elektron di ionosfer (Kamogawa, 2004; Pulinets dan Ouzounov, 2011).

Merujuk pada Gasparani dan Montovani, (1978); Kamogawa, (2004); Pulinets dan Ouzounov, (2011); Li dkk., (2016), anomali TEC berkaitan dengan erupsi cenderung bersifat negatif. Kecenderungan ini disebabkan oleh magma panas yang bergerak naik dari dapur magma akan memicu pelepasan ion positif ke ionosfer yang kemudian mengikat elektron bebas sehingga terjadi penurunan kerapatan elektron atau penurunan nilai TEC. Oleh karena itu sebagai asumsi awal setiap DTEC negatif yang muncul telah dilokalisir sebagai prekursor erupsi, sementara DTEC positif dapat diabaikan. Data menunjukkan bahwa sebagian besar DTEC negatif teramati pada stasiun PIMO. Anomali-anomali terjadi pada tanggal 30 Juni , 4 Juli, 7 - 8 Juli, dan 10 - 11 Juli 2011. Anomali pada tanggal 10 dan 11 Juli 2011 diduga berkaitan dengan erupsi gunung Lokon pada 14 Juli 2011, karena pada tanggal 9 Juli 2011 telah terjadi peningkatan tremor seiring dengan peningkatan tekanan pada gunung Lokon yang mencapai puncaknya pada tanggal 11 Juli 2011 (Kristianto dkk, 2012). Anomali pada tanggal $10 \mathrm{Juli}$ 2011 dapat diasumsikan juga sebagai prekursor gempa bumi yang terjadi di wilayah Filipina pada tanggal 11 Juli 2011 (lihat Tabel 2). Anomali negatif lainnya yang terjadi tidak diasumsikan sebagai prekursor letusan gunung Lokon karena anomali tersebut tidak didukung oleh adanya aktivitas yang signifikan dari gunung Lokon menjelang erupsi seperti peningkatan tremor, pancaran abu, dll. Berdasarkan data-data anomali negatif diatas, dapat disimpulkan bahwa anomali negatif pada tanggal 11 Juli 2011 yang ditunjukkan oleh lingkaran merah merupakan prekursor letusan gunung Lokon pada tanggal 14 Juli 2011 (gambar 4). Anomali tersebut diduga berkaitan dengan proses pergerakan magma, fluida, dan gas dari dalam gunung ke permukaan (Gasparani dan Montovani, 1978; Kamogawa, 2004; Pulinets dan Ouzounov, 2011; Li dkk., 2016).

\section{Kesimpulan}

Berdasarkan pengolahan dan analisis data yang telah dilakukan, dapat disimpulkan bahwa anomali TEC yang teridentifikasi sebagai prekursor letusan gunung Lokon 14 Juli 2011 terjadi pada tanggal 11 Juli 2011.

\section{Daftar Pustaka}

Abidin, H.Z. 2000. Penentuan Posisi Dengan GPS dan Aplikasinya. PT. Pradnya Paramita, Jakarta.

Akhoondzadeh, M. 2012. Anomalous TEC variations associated with the powerful Tohoku earthquake of 11 March 2011. Nat. Hazards Earth Syst. Sci. $12: 1453-1462$.

Arikan, F., C.B. Erol, dan O. Arikan. 2003. Regularized estimation of vertical total electron content from Global Positioning System data. Journal of 
Geophysical Research: Space Physics. 108(A12) : 1-12.

Gasparini, P., dan M. S. M. Mantovani. 1978. Radon Anomalies and Volcanic Eruptions. Journal of Volcanology and Geothermal Research. 3 : 325341.

Global Volcanism Program, 2011. Report on Soputan (Indonesia). In: Wunderman, R (ed.), Bulletin of the Global Volcanism Network, 36:11. Smithsonian Institution. USA.

Global Volcanism Program, 2015a. Report on Marapi (Indonesia). In: Venzke, E (ed.), Bulletin of the Global Volcanism Network, 40:5. Smithsonian Institution. USA.

Global Volcanism Program. 2015b. Report on LokonEmpung (Indonesia). In: Venzke, E (ed.), Bulletin of the Global Volcanism Network, 40:12. Smithsonian Institution. USA.

Global Volcanism Program, 2017. Report on Semeru (Indonesia). In: Venzke, E (ed.), Bulletin of the Global Volcanism Network, 42:5. Smithsonian Institution. USA.

Kamogawa, M. 2004. Atmospheric field variations before the March 31, 2002 M6.8 earthquake in Taiwan. J. Terres. Atmosph. Ocean. 15 (3) : 397412.

Kristianto., H. Gunawan., N. Haerani., I. Mulyana., A. Basuki., S. Primulyana., dan F. Uskanda. 2012. Bina Gejala awal letusan Gunung Lokon Februari 2011 - Maret 2012. Jurnal Lingkungan dan Bencana Geologi. 3(3): 151 - 168.

Li, W., J. Guo., J. Yue., Y, Shen., dan Y. Yang. 2016. Total electron content anomalies associated with global VEI 4 + volcanic eruptions during 20022015. Journal of Vulcanology and Geothermal Research: Validation using model simulations, Radio Sci. 325 : 98-109.

Nenovski, P.I., M. Pezzopane, L. Ciraolo, M. Vellante, U. Villante, M. De Lauretis. 2014. Local Changes In The Total Electron Content Immediately before The 2009 Abruzzo Earthquake. Advances in Space Research. 55 : 243-258.

Pulinets, S., dan D. Ouzounov. 2011. LithosphereAtmosphere-lonosphere Coupling (LAIC) model An unified concept for earthquake precursors validation. Journal of Asian Earth Sciences. 41 : 371-382.

United States Geological Survey. 2011. Earthquake Data. https://earthquake.usgs.gov/earthquakes/ search/. [11 April 2019].

World Data Center for Geomagnetism. 2011. Final DST Index. http://wdc.kugi.kyoto-.ac.jp/dstfinal/ index.html. [12 April 2019]. 